Island Studies Journal, Vol. 11, No. 2, 2016, pp. 417-430

\title{
Enduring perceptions: Placenaming and the perception of Louisiana's salt dome islands
}

\author{
Philip Hayward \\ University of Technology Sydney and Southern Cross University \\ Australia \\ prhshima@gmail.com
}

\begin{abstract}
Salt domes are geological features that occur when areas of salt deposits are pressured into layers above them, causing dome shaped distortions in horizontal strata. In some instances, the distortions protrude above flat areas of land or else appear underwater as seamounts. In the case of the five Louisiana salt dome hills considered in this article, their distinct elevation above the swampy bayous and flatlands surrounding them has led to their characterisation as islands by indigenous Atakapa-Ishak peoples and by subsequent Francophone and Anglophone settlers. The article considers the ways in which the five salt domes' islandness has been perceived, enhanced and/or undermined by various local inhabitants and/or the industries that have operated on them. Discussion of these aspects involves consideration of the manner in which the salt dome islands' islandness is mutable and complex, particularly with regard to human impacts. This mutability is discussed with regard to both individual island placenames and the islands' overall designations.
\end{abstract}

Keywords: Avery, Belle, Cote Blanche, connectivity, islandness, insularity, Jefferson, Louisiana, placenames, salt dome islands, Weeks

(C) 2016 - Institute of Island Studies, University of Prince Edward Island, Canada.

\section{Introduction}

The islands discussed in this article have a common antecedence. They result from the shallow sea that covered the south-eastern area of the (present-day) United States during the middle Jurassic period. The waters of this sea have long since retreated but their saline content has remained as a sedimentary layer. Subsequent periods of alluvial deposition covered these deposits and exerted pressure on them, pushing sections up and creating dome-like distortions of strata. Most of the resultant salt domes are sub-surface features that are only revealed by geological surveys and/or drilling; but some manifest at surface level as low lying, dome shaped hills that aggregate salt and oil deposits under their crests. The five salt dome islands in Louisiana that are analysed in the article are distinct, within the US South East, in that they occur in predominantly flat and often swampy or riverside locations that result in the domes' appearance and perception as islands. The following discussions identify aspects of human perception of the islands and related patterns of settlement, development and exploitation.

The islands addressed in this article are particularly pertinent for contemporary analysis as they occur between those classic water-hemmed locations that were the sole focus of Island Studies in the 1980s-2000s and those related peninsular and/or metaphoric entities that have 


\section{P. Hayward}

been the subject of recent discussions within the field. ${ }^{1}$ As Jackson (2008, pp. iv-v) has identified,

Islandness is an ambiguous concept, partly due to the openness/closure of island boundaries (openness refers to connectedness with the wider world and closure relates to insularity)... Islandness can be diminished by increasing accessibility (a form of greater boundary openness), such as bridges or faster ferries, or by developments that do not pay due heed to principles of sustainability or specificities of island context.

Expanding on the ambiguity that Jackson notes above, Barrowclough's research on historical aspects of the (now land-locked) Isle of Ely in the English county of Cambridgeshire is particularly pertinent for this article. Opening by identifying his starting point as "a definition of islands that goes beyond geographical isolation to consider islands as social constructs insofar as they reflect feelings of isolation, separateness, distinctiveness and otherness" (2010, p. 27), he develops a case study of the (now) "dry island" of Ely. His focus on providing "cognitive mappa" (ibid.) - that is, "a mental map of the inhabitants of a specific island that will take account of both social patterns of inter-island interaction, and of the place of the island within a network involving the wider outside world" (ibid.) is echoed in this article and explored with particular regard to patterns of placenaming that reflect such mental maps during various stages of settlement of the south east of Louisiana. Posing the Louisiana salt dome islands as located somewhere between the 'true' island and metaphorically islanded 'elsewhere', discussions attempt to identify how the five islands' islandness has been historically constituted, both in terms of their perception as such and with regard to changes to their nature, structure and spatial organisation. This article echoes Fleury and Raoulx (2016) by primarily addressing categorizations of particular types of features and by seeking to understand human perception and usage of these via their nomenclative histories. And so, unlike classic toponymic studies, such as those presented elsewhere in this thematic section of Island Studies Journal, this paper is not as concerned with the derivation and nature of individual placenames as more general characterizations of particular landscape features.

\section{The five islands}

People do not behave under the influences of their senses alone but also through their past experiences. These experiences contribute to each individual's unique view of the world, a kind of cognitive map that guides them. Groups of people living together tend to develop a shared view of the world and similar cognitive maps, which in turn influence their group material culture (Barrowclough, 2010, p. 31).

Louisiana's five salt dome islands - Avery, Belle, Cote Blanche, ${ }^{2}$ Jefferson and Weeks - are clustered to the north of Vermilion Bay, on the Gulf of Mexico (Figure 1). They rise over 20 metres above their surrounding marshlands, with Avery having the highest elevation, at 46

\footnotetext{
${ }^{1}$ Examples of the latter include the project and content of the new journal Urban Island Studies, which analyses both urban islands and parts of cities and mainlands that might be considered 'islanded' and/or 'archipelagized' by various factors, and the recent theme issue of the journal Shima 10(1) on peninsular 'almost islands'.

${ }^{2}$ NB present-day placenames in Louisiana have dispensed with the accents that appear in French language terms such as Ille and Côte.
} 
metres, and are between one and two kilometres in diameter (GulfBase.org, 2016). While they are not traditional islands, in the sense of being parcels of land wholly surrounded by marine, lacustrine or riverine water, humans visiting and/or inhabiting the area they are located within have produced a series of characterisations that reflect their identification as such.

\section{Figure 1: Map of the five salt dome islands and surroundings.}
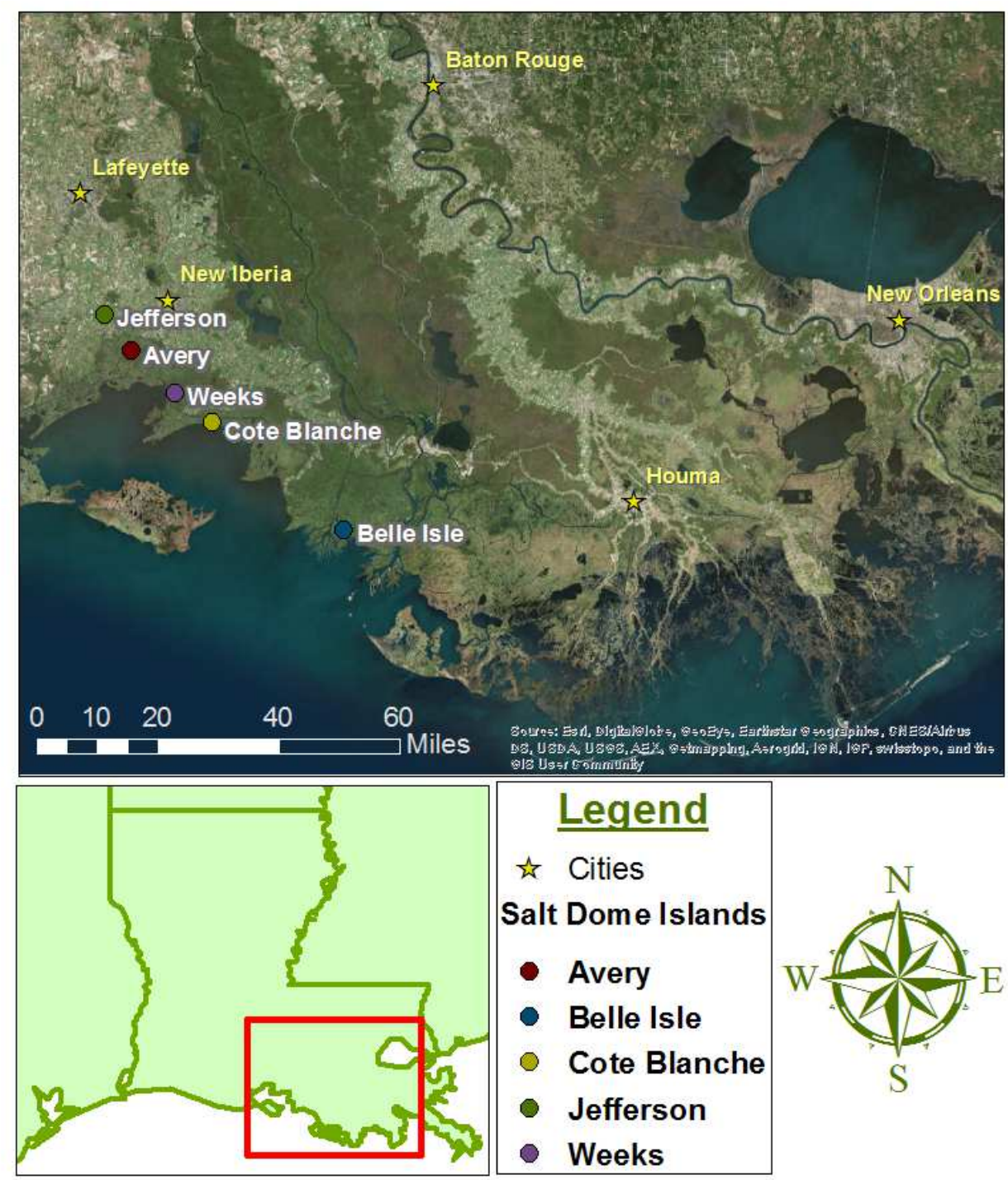

Source: (ㅇ 2016 - Alahna Michele Moore.

The Atakapa-Ishak people who inhabited the region at time of early European contact and subsequent settlement dwelt on areas of elevated dry land during their seasonal migrations through the region. Given that neither the swampy bayou land that occupies a substantial area of the region nor the dense forest that covered the salt dome islands were particularly amenable for easy transit between locations, the Atakapa-Ishak relied heavily on waterways for navigation. Their standard means of transport were single-hulled canoes made from the hollowed out trunks of water-resistant woods that grew on the salt dome islands. These canoes 


\section{P. Hayward}

could be as long as nine metres and could hold between 15 and 30 people, dependent on what else was being carried in the hulls.

The Atakapa-Ishak also utilized their canoes to gather foodstuffs, including marine animals (primarily fish and shellfish but also alligators) and marine plants (Schweid, 1999). The American lotus (Nelumbo lutea) was a dietary staple for the Atakapa-Ishak, who referred to it as kat'ho'pc (Gatschet and Swanton, 1932: 9). The plant has a leafy component that supports a central flower that floats on the surface and a long stalk that connects to a rhizomatic root. Both the rhizome and seeds are edible and nutritious, the root providing a starchy vegetable that can be stored as a winter food source (when other foods are less available) and the seeds can either be eaten raw or roasted to make a flour for a porridge (Swan, 2010). ${ }^{3}$

The Atakapa-Ishak's engagement with the aquatic elements of their southern Louisiana locale for core livelihood activities ${ }^{4}$ invites characterization in terms of my description of the "aquapelago" as an integrated marine and terrestrial assemblage generated by human habitation and livelihood activity (Hayward, 2012). Fittingly, in this regard, the (now inactive) Atakapa-Ishak language that was preserved in the 1800s and early 1900s (Gatschet and Swanton, 1932) included a wide variety of words for types of waterways and marshes and for positionality within these. While Atakapa-Ishak placenames for the five salt dome islands have not been preserved, the language included a specific term for small, tree-covered areas of elevated lands (such as the salt domes): $k a^{\prime} k$ hidso'm (ibid., p. 42). In a broader context, some insight into the cultural-spiritual 'imaginary' of the Atakapa-Ishak can also be gleaned from their creation story, which conceives the tribe as originating from the sea. Another element of their folklore includes the story of a massive inundation of southern Louisiana that was only survived by those who had access to areas of high ground, which were 'islanded' during a cataclysmic flood, with the survivors going on to form the nucleus of the latter day AtakapaIshak people (Swanton, 1911, p. 356, Darensbourg, personal.communication, 2 April 2016). ${ }^{5}$

The earliest surviving names for individual salt dome islands are Francophone ones that arose during initial French settlement of the southern part of the (present-day) state in the late $17^{\text {th }}$ Century or following the relocation of Francophone Acadians to the region after their expulsion from British controlled areas of (what are now) Canada's Maritime provinces in the mid-18th Century. ${ }^{6}$ As Nash and Low (2015) have argued, placenaming is a particularly significant activity for new inhabitants of regions. They identify it as being "integral to processes of place creation, belonging and attachment" and characterize it as providing a relative sense of "stability" by virtue of placenames' ability to "memorialize persons, events and social relations", "imprinting the landscape" with reminders and associations with human actions upon it and sensibilities concerning it (ibid., p. 405). The renaming of locations by successive social groups and/or individual land owners thereby represents attempts to

\footnotetext{
${ }^{3}$ The plant also featured in a variety of other First Nations peoples' diets - such as that of the Osage, who originated in the Ohio River Valley (Swan, 2010).

${ }^{4}$ The Atakapa-Ishak people also inhabited drier areas of central Louisiana where they practiced significantly different hunting and livelihood patterns, such as hunting buffalo, preserving its meat through smoking and trading this with other tribes in the area. (Darensbourg, personal communication, 2 April 2016).

${ }^{5}$ Swanton's account derives from information obtained from a man named Murray, reported in a document written in the early 1800s by Martin Duralde, who was based in the area at the time. Darenbourg has confirmed that this is the accepted creation myth in contemporary Atakapa-Ishak culture (Swanton, op. cit.).

${ }^{6}$ Nova Scotia, New Brunswick and Prince Edward Island. Francophone settlers were also expelled from adjacent areas of what is now northern Maine and eastern Quebec.
} 
variously re-inflect prior names or replace them with ones more suited to the group's or individual land owner's perceptions. The new names also serve the important function of asserting control and ownership over particular places.

A number of placenames from the Francophone period of settlement reflect a perception of the marsh and prairie land of southern Louisiana as having sea-like flats, features that protrude above these and adjacent coastal slopes. ${ }^{7}$ This may, in part, reflect seasonal variations in the landscape, in that the water-logged nature of much of southern Louisiana's terrain results in shallow pools of water covering large, low-lying areas after substantial periods of rain, creating temporary shallow expanses of water that are easily perceived as marine-like. Similar to Côte Blanche, which has retained its $18^{\text {th }}$ Century Francophone placename to the present, albeit shedding its circumflex accent along the way, three of the other salt dome hills carried the former appellation during the period of initial Francophone settlement: Côte de Coiron (now Avery Island), Grand Côte (Weeks Island) and Côte Carlin (Jefferson Island). ${ }^{8}$ In traditional French language usage the term côte refers to a hillside or an area of coast or riverbank, thereby allowing a degree of ambiguity and slippage to its characterisation of the Louisiana locales discussed in this article. ${ }^{9}$ While the islands were (and are) encircled by land, this is often dominated by bayous (marshy inlets). In several instances, the junction points of island slopes with surrounding flats are also marked by streams, flowing off and/or around the protuberances.

Before Côte de Coiron became known as Avery Island it was also known as La Petite Anse, ${ }^{10}$ (meaning 'the little cove', on account of the appearance of an area of its slopes). ${ }^{11}$ The current designation of the fifth salt dome, Belle Isle, combines a French adjective (meaning 'beautiful') with an abbreviated Anglophone term for island (rather than the original French Île). ${ }^{12}$ While the reason for its specific designation as an île (rather than côte) by Francophone settlers is not recorded, its location close to Vermilion Bay and immediately south west of the (tidal) Belle Isle Lake may have given it a more distinct sense of (conventional) islandness. It

\footnotetext{
${ }^{7}$ The online heritage resource thecajuns.com includes a section on 'Louisiana History: Old and New Place Names' (n.d.) that details the names given to various locations by (what it identifies as) Cajun (i.e. Acadian) settlers. My caveat to the resource concerns the Francophone history of the region before Acadian settlement and an ambiguity about when local place-naming conventions may have developed.

${ }^{8}$ Two of the former names are easily translated - Large (Grand) and White (Blanche). While the former is a straightforwardly descriptive term, the derivation of the latter is more obscure. An official Louisiana place marker erected at Cote Blanche identifies that, "After the hurricane of Cheniere Caminada in 1893, a group of refugees settled in this area. Because many of them painted their homes white, the settlement became known as 'La Cote Blanche,' a village of white houses." This appears to be wrong however as the term Côte Blanche is present in several written descriptions of the area several decades before the hurricane related settlement. The other two names are those of individuals associated with the locations. Coiron was the surname of an individual who claimed ownership of Avery Island in the 1790s and Carlin is also an (anglicized) form of the Gaelic surname Caireallain/ O'Cearbhallain.

${ }^{9}$ The salt dome islands were not the only elevated and/or distinct landscape features to carry this appellation. Other placenames, such as Cote Vache in Vermilion County, referred to elevated dry pasture area used for cattle grazing. Significantly, the former term also became 'island' in its Anglophone version, Cow Island.

${ }^{10}$ Signage at the Avery Island Museum also identifies that the island was briefly known as Isla Cuarin: the former term being the Spanish word for island and the latter being a version of an owner's name (see Note 8 above).

${ }^{11}$ It should be noted that there is some slippage between reference to a particular feature of the island as 'Petit Anse' and of the island as a whole in various sources. Following its second French language appellation it was first known as McCall and then Marsh and, finally, Avery Island.

${ }^{12}$ Belle Île is a common designation in French and is, for instance, the name of an island off the south coast of Brittany.
} 


\section{P. Hayward}

is significant that while the term île was not widely used as a placename for elevated areas by French and/or Acadian settlers, the term is used in France to refer to elevated areas in marchlands that are surrounded by water after intense rainfalls, such as L'île Marie in Normandy's Cotentin swamp. ${ }^{13}$

The use of these French coastal/marine terms for landscape features attracted comment from Louisiana author Harnett Kane in 1943. In The Bayous of Louisiana, he asserted that when early Francophone settlers,

...came upon a dark patch of wood, surrounded by the lighter grass, they called it an 'île.' Where the wood jutted sharply into the prairie like an edge of land in the water, it was a 'pointe.' A section partly protected by extensions of the trees was an 'anse' or bay. (ibid., p. 278) ${ }^{14}$

Seeking a reason for the ascription of coastal terms to inland areas, Kane asserted that,

Early visitors were reminded of wide billows of a vast sea; viewed from a point on one of these mounds, the uniform surfaces of grass change like waves as the wind slips over them. The Acadians also were impressed with this resemblance. The Acadian, of course, had a background of life at the water's edge, and this he demonstrated in other ways. When he wanted to cross the prairie, he used the word 'naviguer' [navigate]. He said that he would 'embarquer' in his buggy or 'mettre la voile' [set sail] on the green; and he 'moored' his mount. (ibid., p. 278)

Whatever the accuracy of his latter characterisations, the former ones are somewhat tendentious. The reference to "early visitors" being "reminded" of the sea is not substantiated and the characterization of Acadians as a primarily coastal people belies the variety of inland locations they were deported from and in which they farmed and traded. Surviving records of Francophone placenames in areas of present-day Canada settled by the Acadians does not indicate that the terms anse, pointe or côte were used for anything but coastal locations. ${ }^{15}$ Given the substantial degree of interaction and intermarriage the Acadians had with the Atakapa-Ishak tribe in the region (Darensbourg, personal communication, 2 April 2016), it is as likely that their placenaming reflected Atakapa-Ishak perceptions of south Louisiana filtered through their own conceptual/linguistic heritage.

Similar sensibilities carried over into Anglophone placenaming traditions, perceptions of the salt dome hills as islands being prevalent in several Anglophone descriptions of the locations published in the 1800s. Dimitry, for instance, identified that the area analysed in this article contained "five islands of firm bluff land, which rise, mountain-like above the vast sea marsh" (1877, p. 168). With regard to English language usage, the current designation of the five Louisiana inland salt dome hills as islands has some precedence. There are various English placenames that refer to islands/isles that are actually peninsulas (such as the Isle of Dogs, in East London) or, most pertinently for this article, locations that are (or were once) areas of

\footnotetext{
${ }^{13}$ Thanks to Christian Fleury for this information and example (personal communication, 22 March 2016).

${ }^{14} \mathrm{He}$ also identified that the term côte was applied to hillsides, as in the colourfully named, Côte Gelées ('frozen hillsides') (ibid., p. 279).

${ }^{15}$ See, for instance, http://www.acadian-home.org/places-yesterday-today.html
} 
elevated, dry land within bogs (such as the aforementioned Isle of Ely in Cambridgeshire). ${ }^{16}$ Louisiana placenaming is congruent with aspects of this tradition. It is also significant to note that some non-Anglophone countries also use their versions of the term 'island' to describe a variety of locations. In Japan, for instance, the terms shima/jima are applied to both standard water-hemmed islands and other locations that are geographically isolated and/or specifically constituted (Suwa, 2006).

Visiting the islands in the mid-2010s provides a variety of impressions of islandness. Jefferson Island is the least archetypal island in terms of its being approached via three main roads across fields, with the largest lined with oak trees that lead the visitor up to the historic house and adjacent buildings on its peak. ${ }^{17}$ Its islandness is therefore primarily experienced in terms of its distinct elevation from surrounding flatlands and the distinct nature of its patches of native forest, amongst which is located the Rip Van Winkle ornamental gardens. The roadway and paths around the house keep visitors within an exterior location that offers no signposting of its salt mine area, which is approached by other roads (away from the main entrance) and which is marked with deterrent signs and fences. Within the single island there are effectively two 'islanded' components, a highly maintained park-like space, which constitutes the island's tourism attraction, and a rigidly separated and effectively concealed oil facility. The two offer very different senses of space.

Avery Island has a more classic sense of islandness or, rather, bridged islandness (Baldacchino, 2007), in terms of access being via a bridge monitored by a gatehouse (Figure 2). This bridge crosses a body of water named Hayes Coulee, which provides a moat-like perimeter to the eastern half of the island. As with several previously discussed placenames, the latter designation is significant. Along with Hayes (being a surname), ${ }^{18}$ the Louisiana French term coulee derives from the French term coulée, meaning a gully through which water flows. Edwards and de Verton (2004, p. 73) have identified that in Louisiana the term was originally used to refer to gullies that ran with water during wet weather but later came to be applied to streams that flowed constantly as a result of their being dredged and/or canalized. The linguistic history of the term neatly inscribes a history of the development of waterways around the perimeter of Avery island that saw the location shift from being one that was periodically islanded, as a result of being surrounded by full gullies after sustained rainfall, to one that was more permanently islanded as a result of dredging and canalisation that enabled access to Avery's salt mining operations to occur by water. This latter aspect is most apparent now in the form of the dredged deep water canal that penetrates into the hub of the island's mining activity in the south west of the island and links round to a smaller facility on the south east corner. In this manner, the term coulee carries within it the history of Avery's Island's increased islandization as a result of human development activities on a location that was formerly more of a figurative island. Like Jefferson, Avery island also has individual islanded components, a similarly highly maintained tourist facility with a mixture of lawns, ornamental

\footnotetext{
${ }^{16}$ In historical terms, the elevated area around Glastonbury, once surrounded by marshland, was famously known as the Isle of Avalon, as celebrated in Arthurian mythology.

${ }^{17}$ Jefferson Island's name derives from that of famous actor Joseph Jefferson, who acquired what was then called Orange Island in 1870. Jefferson's fame largely derived from his playing the role of Rip Van Winkle (a character who slept through the Civil War and avoided its traumas) in stage and screen adaptations of Washington Irving's eponymous 1819 short story. In addition to giving his actual name to the island, his fictional role was inscribed in the name of the garden of exotic plants established on the island by John Lyle Bayless Jr in the late 1950s, (suggesting a similar timeless quality to his gardens).

${ }^{18}$ I have been unable to ascertain the significance of the coulee's association with the specified individual.
} 
gardens and remnant old growth trees, and salt and oil mine areas that are preceded by 'no trespassing' signs and then marked by fences and by security patrols.

\section{Figure 2: Approach to Avery Island and bridge gatehouse ${ }^{19}$.}

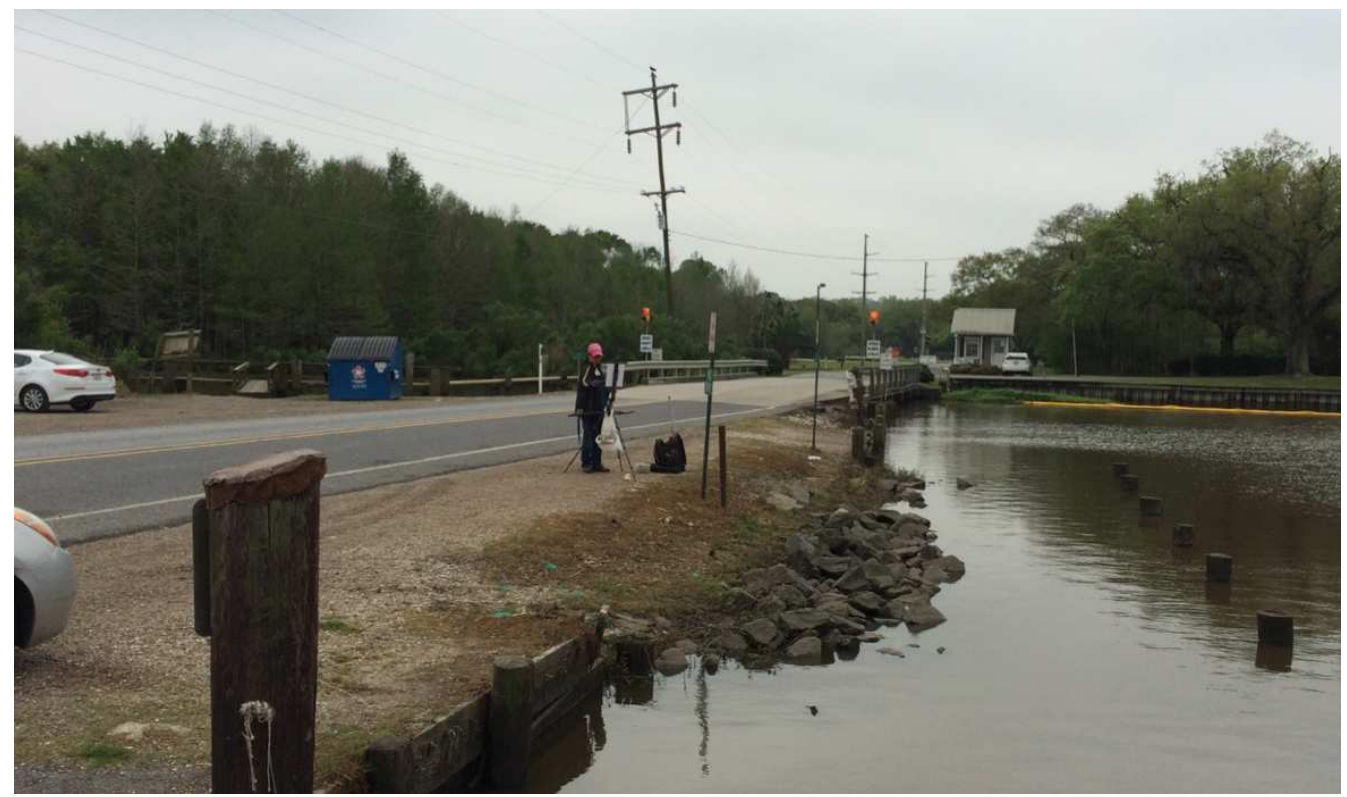

Source: Photograph by Philip Hayward, ( 2016.

Weeks Island presents itself somewhat paradoxically to the traveller in that despite being surrounded by water around over $90 \%$ of its perimeter, it can be easily accessed via two roads. One crosses on to the island via its only non-water rimmed point at the south east, and the other, at its north-western point, runs across a narrow causeway. Until the late 1960s the island supported a community whose adults mainly worked in the salt mine and who could come and go with relative ease. But all residents and, in many cases, their actual homes, were moved off the island in 1969 when the mining company's insurers advised them that volume of material extracted from the mine meant there was a severe risk of surface subsidence. This situation and the continuation of salt and chemical production on the island - despite continuing structural environmental concerns - have led to highly restricted access to the majority of areas.

Cote Blanche Island's islandness is more complex, in that it both has the surrounding waterways that typify the majority of the five salt dome islands and has also been further islanded by its isolation from the mainland on a narrow coastal land strip created through the construction of the Gulf Intracoastal Waterway (GIW) that runs from Brownsville (Texas) to Carrabelle (Florida). Completed in 1949, the GIW was dredged and canalised in order to create a safe navigation passage for barges around the coast of the Gulf of Mexico without exposure to marine navigation hazards and/or interference (see Alperin, 2009 for further discussion) and is therefore particularly convenient for the mineral extraction operations at Avery, Cote Blanche, Jefferson and Weeks islands. As a result of the GIW, Cote Blanche

\footnotetext{
${ }^{19}$ Note the painter in centre of image painting the approach to the island, marking its appeal as a 'beauty spot' in the wider area.
} 
appears more stereotypically as an island in that it can only be accessed by driving onto a ferry barge that relays traffic back and forward to the island from an access road from the main highway. This ferry, which is run by Compass Minerals, which also owns the island's mine, effectively restricts public access by only being open to company employees and thereby functioning as a security checkpoint (Figure 3).

\section{Figure 3: Company ferry at Cote Blanche (crossing the Gulf Intracoastal Waterway).}

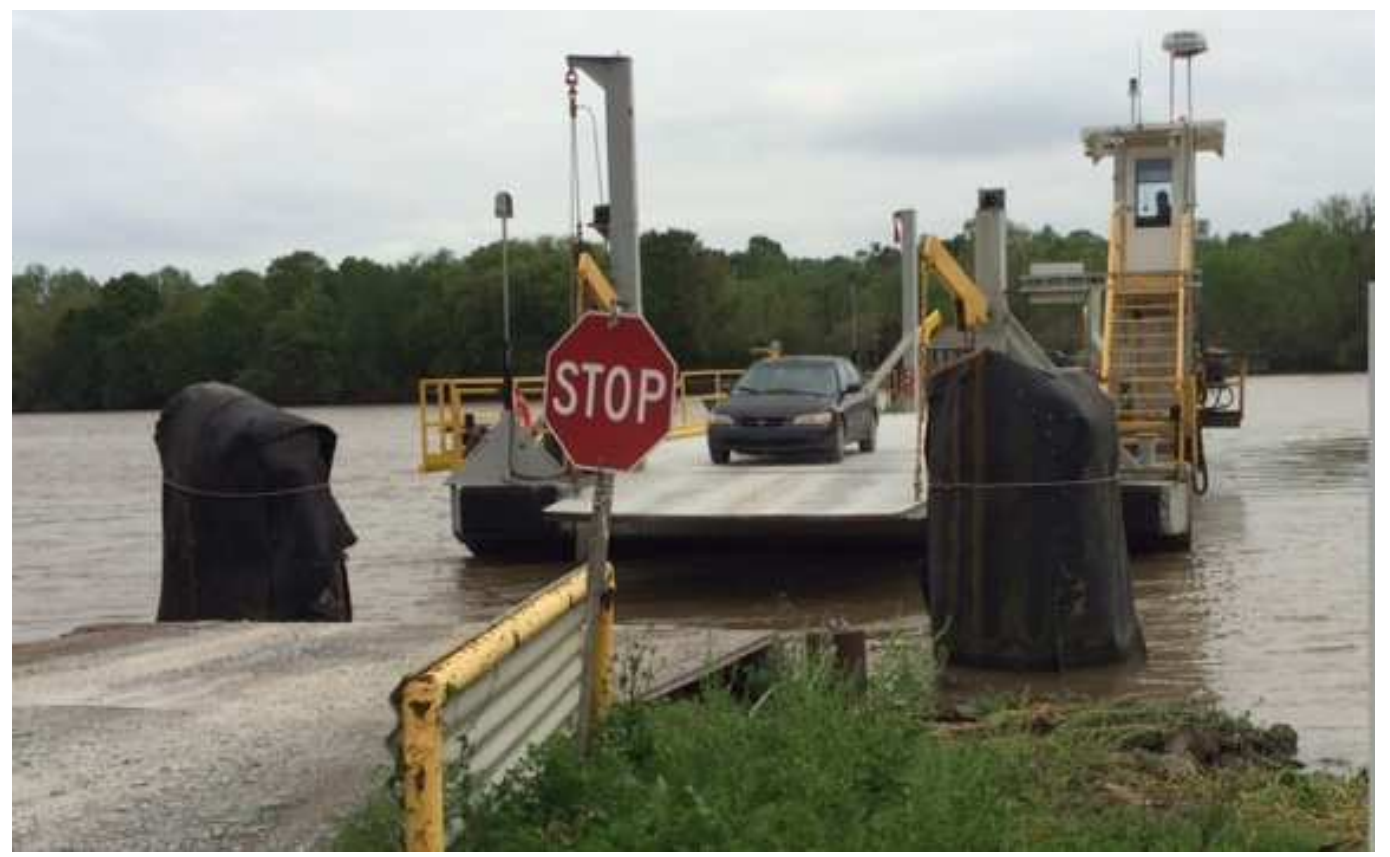

Source: Photograph by Philip Hayward, (O 2016.

Belle Isle is the least developed of the five salt dome islands and has no road access over the numerous bayous, canals and ponds that ring and intersect its lower slopes. As a private island it has no regular ferries and water crossings have to be arranged in advance. It is effectively islanded within its swampy terrain and, currently hosts a small scale tourism business that exploits the island's quietness and isolation.

Since the decommissioning of its salt mine in 1984, Belle Isle has been the first (and only) salt dome island site to experience significant de-industrialisation and related habitat restoration planning (at least in terms of its salt mine related operations - oil well heads still operate in some areas). The current owners of the island have acknowledged the need for restorative work through the formation of a limited company dedicated to pursuing this. Significantly, along with restoration of native habitat, the company's (undated) 'Vision Statement' identifies the borders of the island and its points of interface with surrounding waterways as a priority. Along with categories addressing "Property Protection" (which identifies the protection of "the property from any addition environmental or physical damage from the activities that will occur in the future exploration or mining activities") (ibid.), a further category entitled 'Environmental Enhancement" has the stated goal to, 


\section{P. Hayward}

Restore the property to its natural state. This will be accomplished by looking at the property to determine areas in which land loss has occurred. We will then determine if there are mitigation projects that can be done in order to restore the property back to its natural state ... Research will need to be completed on the determination of the boundaries of the property and the ownership of water bottoms. This will include the boundaries to the south and west along with Belle Isle Lake (ibid.).

While understandable, the desire to return the boundaries of the island to those that existed before salt mining activities took place may be one that is in tension with a looming issue for residents of southern Louisiana more broadly, that of the effect of predicted rises in sea levels due to global warming over the next century. With the predicted rise in sea levels over the next century (Strauss, Kulp and Levermann, 2015), further permanent submersion of lower lying island slopes would be inevitable without major levy building at a level that is highly unlikely to be forthcoming from governmental agencies and/or private sources. In this manner, global warming is likely to obviate the need for the discussions of the Louisiana's salt dome islands' islandness advanced in this article by surrounding them with water in a manner that would merit their discussion within the classic typological framework of mainstream Island Studies.

\section{The five islands' biogeography}

Aside from the five salt dome islands' location with landscapes permeated by water, they merit their designation in terms of their being "habitat islands" in the context of Island Biogeography by virtue of their supporting distinct types of flora and fauna within broader environments not otherwise conducive to their development and/or survival (McArthur \& Wilson, 1967; Whittaker and Fernandez-Palachios, 2007). Similarly, their shared environments in relatively close proximity allow them to function as a "habitat archipelago" within which fauna with sufficient mobility can relocate in incidental and/or seasonal patterns. Consideration of the salt dome islands within this framework complements a broadening in the nature of the field from its original focus on 'classic' water-hemmed islands as "laboratories" for processes of speciation (Whittaker and Fernandez-Palachios, 2007, pp. 53-63) to other types of insular and/or dispersed quasi-archipelagic locations, reflected in a gradual renomination of the field as insular biogeography.

The endogenous flora - and general habit - of the five islands is classified as Salt Dome hardwood forest. This forest, and related vegetation, has developed on fertile loessial soils within a "well-dissected landscape of high, narrow ridges, steep slopes, and deep ravines" (Louisiana Department of Wildlife and Fisheries, 2005, p. 168) that, in combination with their forest covering, have produced cool and moist micro-climates on slopes and in ravines. These forests are classified by the Louisiana Department of Wildlife and Fisheries as "imperilled" due to clearance of forest areas of the five islands for residential purposes, industrial development, roads, pipelines and utilities, overgrazing and/or the spread of exotic species (ibid). This imperilment also effects the distinct fauna that inhabit the islands. Along with other endogenous mammals, the archipelago supports pockets one of the state's most endangered species, the Louisiana black bear (Ursus americanus luteolus). ${ }^{20}$ The island

\footnotetext{
${ }^{20}$ While the bear was removed from the US Department of Wildlife and Forestry's endangered species list in March 2016, this move was not welcomed by conservationists who regarded it as premature (Randall, 2016).
} 
woodlands also form important areas for migratory birds to rest on (Barrow and Fontenot, 2006). Reduction in areas of Salt Dome hardwood forests thereby imperils a range of fauna.

Since the 1800s and early 1900s, a significant cause of clearance of woodland areas on the islands has been agriculture. The experience of Weeks Island is typical in this regard. The island was purchased by the Weeks family in the early 1800s, who cultivated sugar cane, cotton and native scuppernong grapes there. Writing in the late 1800s, when there were still substantial areas of the island that remained undeveloped (and before there was awareness of the dangers of habitat removal and/or the introduction of exotics) the combination of cultivated and wilderness areas of the islands was seen by one writer through an untroubled lens,

At various localities, all over the island, fine, thrifty forest trees may be seen, which add much to the beauty of the scenery. The island, viewed from the highest pinnacle, is picturesque and beautiful beyond anything in the State. Its gentle undulations, its peaks, hills, valleys, ponds, its towering magnolias and noble oaks, its ash and cypress, its fields of blooming cotton and waving cane all inspire the most pleasant emotions in the breast of any beholder who loves to look on nature when she puts on her finest robes and appears in her most bewitching mood. (Perrin, 1891, p. 92)

The combination of sugar cane, indigo or cotton cultivation on flat areas and retention of established native woodland in steeper areas was also a feature of the development of Grand Cote, Weeks and Avery islands. The latter island was also the initial site of cultivation of the Capsicum frutescens chilli peppers required for the manufacture of the McIlhenny family's enduringly successful Tabasco sauce, which required the establishment of processing, storage, transport and administration facilities, that continue to operate on the island as a significant commercial enterprise and local employer. $^{21}$

In one of the many paradoxical acts that have marked human development of Avery island, the reduction in native woodland during the $19^{\text {th }}$ Century was accompanied by a markedly different venture when owner Edward Avery McIlhenny established a colony of snowy egrets (Egretta thula) there in 1895. This action was undertaken in response to the decimation of the species around the Gulf of Mexico by hunters seeking feathers that were then in vogue for women's hats. The colony's location in an area with restricted access allowed the birds an "island refuge" that could not be ensured elsewhere. The colony he established has continued to the present, returning to the island as part of their annual migration cycle. Offsetting this venture, the same individual experimented with breeding the South American nutria (Myocastor coypus) in the late 1930s. The nutria (also known as a coypu) is a beaver like, semi-aquatic rodent whose pelt was a popular as fashion material in the 1930s-1950s. McIlhenny purchased specimens in 1938 to breed for commercial purposes. In 1940 he released a dozen into the marshlands and in 1945 released all of his remaining stock, numbering at least 100 (Bernard, 2002: 290-291). In this context, Avery's islandness in being located within an encircling wetland environment - aided the species' dispersal and the rapidly breeding nutria soon spread throughout southern Louisiana and adjacent states and

\footnotetext{
${ }^{21}$ The chilli peppers are now grown off island, largely in Central and South America, but the manufacturing operation remains on Avery Island, where it is the rationale for and centerpiece of what might be termed 'Tabasco tourism' in the form of a café, museum and gift shop that celebrate and sell the product and associated merchandise.
} 


\section{P. Hayward}

had a severe impact on both human livelihoods and on native species' habitat. ${ }^{22}$ Despite various eradication and control measures, including recent attempts to encourage hunters to shoot them as a food source, the nutria continues to be a damaging invasive species in the region, with an estimated 5 million now present in south Louisiana alone. ${ }^{23}$

The biological history of the salt dome islands and adjacent locales over the last two centuries has underlined the domes' status as islands within the framework of Insular/Island Biogeography with regard to both the fragility of the domes' distinct islanded habitat environments and their potential to allow for rapid dispersal of invasive species into surrounding wetland environments from "dry island" nodes. In this manner, the islands have a mappa within a biogeographical context in a similar manner to the social one outlined above.

\section{Conclusion}

To date, Island Studies has tended to regard islands as defined by their encirclement by water. This article, in contrast, has sought to emphasize the manner in which locations distinguished by their elevation, habitat and/or encirclement by variously liquid, moist and/or dry terrains can also be considered as islands - either by their inhabitants and/or by external researchers without overly distorting the standard conceptual template of islandness. Toponymic study reveals a consistency of patterns of characterization of the protrusive salt dome hills as islands that allows us to accept such characterizations as credible social identifications of (a type of) place. The relatively peculiarity of the Louisiana salt domes' form, and of their perception and identification as islands, is not in dispute but the article has attempted to identify that consideration of them is pertinent with regard to the further development of the scope and ambit of Island Studies and consideration of adjacent geo-social spaces and topics. It also identifies the manner in which islandness is variously open to debate and - seasonally and/or on longer time frames - is mutable, dependent on modifications in sea levels, rainfall patterns and associated inundations. This very mutability is all the more pertinent for island studies in a period in which a number of low-lying archetypal islands are in danger of becoming shallow subsurface features that are uninhabitable for humans and terrestrial fauna and flora alike, becoming "former islands" whose relationship to island studies will be a fundamentally historical one, requiring a new filament within the field.

\footnotetext{
${ }^{22}$ Their burrowing activities undermined levees constructed to maintain rice paddies and crawfish breeding areas, flood levies and banks of waterways in general and their consumption of roots and plants impacted upon sugar cane cultivation and other crops. Their activities also impacted on endogenous species, damaging marshes by consuming plants that bind their soils together, eating shrub and trees seedlings and preventing re-growth. The impacts of this activity also undermine the habitat of fish and mammals who rely on these plants and related habitats.

${ }^{23}$ Bernard (2002) has identified that there were also other nutria farm ventures in Louisiana in the period and that the present population may have derived from multiple sources.
} 


\section{Acknowledgements}

Research for this article was conducted as part of a visiting research fellowship at the Midlo Center for New Orleans Studies at The University of New Orleans. Thanks to Connie Zeanah Atkinson from the Center for facilitating this project, to Alahna Michele Moore for her research assistance and to Wilma Subra for her assistance with field research. Also thanks to Dr Jeffery Darensbourg, Tribal Councilperson and Alligator Band Head, Atakapa-Ishak Nation of Southwest Louisiana and Southeast Texas, for his insights into the indigenous history of the region and to Craig Colten and Christian Fleury for their additional assistances with research queries.

\section{References}

Alperin, H.M (2009). History of the Gulf intracoastal waterway. Alexandria: National Technical Information Service.

Baldacchino, G. (Ed.) (2007). Bridging islands: The impact of fixed links. Charlottetown, Canada: Acorn Press.

Barrow, W., and Fontenot, B. (2006). Vanishing before our eyes: Louisiana Cheniere Woods and the birds that depend on them. Barataria Terrrebonne National Estuary Program. Retrieved from: http://www.btnep.org/Libraries/Publications/Chenieres_Vanishing_Before_Our_Eyes.s flb.ashx

Barrowclough, D. A. (2010). Islandscapes, imaginary and real. Ely: the case of the dry island. Shima: The International Journal of Research into Island Cultures 4(1), 27-46.

Belle Isle LLC (n.d.). Mission statement. Retrieved from http://www.belleislellc.com/Belle_Isle/Mission_Statement.html

Edwards, J. D., and de Verton, N. K. Pecquet du Bellay (2004). A Creole lexicon: Architecture, landscape, people. Baton Rouge LA: Louisiana State University Press.

Felterman, L. (2001). Belle Isle - "Beautiful Island" - Eastern most island of the Five Jewels - St Mary Parish - Louisiana. Self-published. Retrieved from http://wilsonspix.net/Belle-Isle/Lee-101.htm

Fleury, C. and Raoulx, B. (2016). Toponymy, taxonomy and place: the concepts of presqu'île and péninsule. Shima 10(1), 8-20.

Gabrey, S., Kinler, N. and Elsey, R. (2009). Impacts of nutria removal on food habits of American alligators in Louisiana. Southeastern Naturalist 8(2), 47-354.

Gatschet, A., and Swanton, J. (1932). Dictionary of the Atakapa language, Washington DC: Smithsonian Institute. Retrieved from https://texashistory.unt.edu/ark:/67531/metapth20200/m1/74/

GulfBase.org (2016). 'Five islands', entry in Resource database for Gulf of Mexico research. Retrieved from http://www.gulfbase.org/reef/view.php?rid=five1

Hayward, P. (2012). Aquapelagos and aquapelagic assemblages. Shima: The International Journal of Research into Island Cultures 6(1), 1-11.

Jackson, R. (2008). Islands on the edge: exploring islandness and development in four Australian case studies. PhD thesis, Hobart, Australia: University of Tasmania.

Kane, H. (1943). The Bayous of Louisiana. New York: W. Morrow \& Co. 
Louisiana Department of Wildlife and Fisheries (2005). Conservation habitats and species assessments \#25: Salt Dome Hardwood Forest, 168-170.

MacArthur, R., and Wilson, E. O. (1967). The theory of island biogeography. Princeton NJ: Princeton University Press.

Nash, J., and Low, M. (2015). Language and place knowledge on Norfolk island. Ethnos: Journal of Anthropology 80(85), 385-408.

Perrin, W. H. (1891). History of Iberia parish. Houston TX: Gulf Publishing Co.

Randall, K. (2016, March 9). La: Black bear taken off endangered list. Daily Comet. Retrieved from http://www.dailycomet.com/article/20160309/ARTICLES/160309665

Schweid, R. (1999). Hot peppers: The story of Cajuns and capsicum. Chapel Hill NC: University of North Carolina Press.

Strauss, B., Kulp, S., and Levermann, A. (2015). Carbon choices determine US cities committed to futures below sea level. Proceedings of the National Academy of Sciences of the USA 112(44), 13508-13512.

Suwa, J. (2007). The space of Shima. Shima: The International Journal of Research into Island Cultures 1(1), 6-14.

Swan, D. (2010). The North American lotus (Nelumbo lutea Willd): Sacred food of the Osage people. Ethnobotany Journal, $8 . \quad$ Retrieved from: https://scholarspace.manoa.hawaii.edu/bitstream/10125/21013/1/i1547-3465-08249.pdf

Swanton, J. (1911). Indian tribes of the lower Mississippi valley and adjacent coast of the Gulf of Mexico. Washington DC: Government Printing Office.

Whittaker, R., and Fernandez-Palacios, J.M. (Eds.) (2007). Island biogeography: Ecology, evolution and conservation ( $2^{\text {nd }}$ edn). Oxford: Oxford University Press.

www.thecajuns.com (n.d.). Louisiana history: Old and new place names. Retrieved from http://www.thecajuns.com/oldnew.htm

\section{Personal Communications}

Darensbourg, Jeffery (Tribal Councilperson and Alligator Band Head, Atakapa-Ishak Nation of Southwest Louisiana and Southeast Texas), interview in New Orleans, 5 April 2016.

Fleury, Christian, email communication, 22 March 2016. 